\title{
Investigating the Impact of Internal Communication and Organizational Structure on Employees' Communication Satisfaction within Moroccan Higher Education Institutions
}

\author{
Abderrahmane Azennoud \\ Al Akhawyan University, Ifrane, Morocco \\ A.Azennoud@aui.ma \\ Bani Koumachi
}

Sidi Mohamed Ben Abdellah University, Fes, Morocco

badrekoumachi@yahoo.com

\begin{abstract}
The study investigates the type of relationship that exists between internal organizational communication and internal organizational structure and the potential effect they might have on the employees' level of organizational communication satisfaction in two Moroccan institutions of higher education. A mixedmethod case study design is used for the collection, the analysis, and the interpretation of data with concurrent triangulation methodology as a research strategy. The findings indicate that there is a strong negative relationship between internal organizational communication and internal organizational structure. The majority of the respondents are satisfied with communication within the case organizations and use a mixture of formal and informal internal organizational communication as well as an ambidextrous internal organizational structure. The results also show that there are also statistical differences among the employees' level of organizational communication satisfaction.
\end{abstract}

Keywords: internal communication, internal structure, communication satisfaction

\section{INTRODUCTION}

Communication links people together and creates complex relationships between them particularly in a workplace (Clegg et al, 2006). A workplace is created and given 'meaning' when employees from different organizational ranks work together towards one particular organizational goal which is unattainable if there is no communication. Communication is at the heart of the meaning-making process not only in political, economic and psychological fields but also in the organizational communication field (henceforth OC). Additionally, communication serves in the works of developing, organizing and disseminating knowledge within the organization through communicative acts (Duncan \& Moriarty, 1998 reported in Wang \& Pizam, 2011, p. 189). Thus, communication is more than just a transmission process. Indeed, its role is decisive in the failure or the success of any given organization (Bernold \& AbouRizk, 2010). This view is not only limited to business organizations but also concerns educational organizations irrespective of their size or form. In such types of organizations, communication or particularly internal organizational communication (henceforth IOC) is considered as "the glue that binds the learning community" (Ubben et al. 2007, p. $312)$.

In like vein, IOC has become salient as organizations have come to the conclusion that good IOC can "contribute to improved performance and also help resolve any issues that might give rise to conflict" (Butterick, 2011, p. 103). However, the lack of effective IOC can create mistrust in a workforce, and therefore affects negatively the effective and the efficient attainment of organizational goals. IOC is best explained with reference to "The goals of interaction in which the communication occurs" (Cushman \& Cahn, Jr., 1985, p. 101).

An organization's image is especially critical to its internal audience because employees' perception of the organization influences their morale, productivity, goal execution, and overall satisfaction (Mathisen \& Einarsen, 2004). Therefore, organizational leaders must evaluate the most effective ways to ensure that employees have a positive perception of the organization and how they are satisfied 
with the IOC within the organization. Here comes into play the salience of organization communication satisfaction (henceforth OCS). This can be quite challenging since peoples' perceptions are influenced by a wide range of factors and personal attributes as researchers have found that internal organizational structure (henceforth IOS), leadership style, decision-making processes, and relationships significantly influence employees' level of OCS in an organization as well as its effectiveness (Potosky \& Ramakrishna, 2002).

IOC and IOS are two particular components of organizational aspects that are pertinent components of organizational relationships in this study. These two constructs have been chosen as organizational backgrounds because this study primarily has the objective to explore internal relational aspects within two Moroccan institutions of higher education, the Faculty of Law and Economics, Meknes (henceforth the FLEM), and the National School of Agriculture, Meknes (henceforth the NSAM) as two case organizations. Also, as it will be made clear in the research objectives, these are the factors that are supposed to affect the employees' perceptions, attitudes, behaviors, satisfaction and attainment of goals inside organizations (Fournier, 2008; Misner, 2008).

\section{Statement of The Problem}

The study is anchored on the theory that communication is the soul and the lifeblood of any given organization. Starting from the conviction that research on OC is rather fragmented and focuses on specific group or content, rather than on an integrated OC approach including all employees of an organization and that IOC is a multifaceted domain in the sense that it has a bearing on many fields that feed it, the present study is driven by the desire to discover the status of IOC in two academic organizations/institutions of higher education in Morocco and to study the nature of both IOC and IOS and assess the sort of connection between them with the idea to reveal whether they affect the employees' level of OCS.

\section{OBJECTIVES}

The present study is undertaken to find out the current situation of both IOC and IOS, to identify and to categorize their different types as well as to explore thoroughly the role and the extent to which these two variables impact the employees' level of OCS in two case organizations, the FLEM and the NSAM. This study also aims to get a detailed insight into the degree of the employees' level of OCS in the two case organizations through a case study on the basis of which the present study will try to achieve these specific objectives: (1) To identify the nature of both IOC and IOS, (2) to examine the nature of the relationship between IOC and IOS, (3) to investigate the nature of the relationship between overall OCS and both IOC and IOS, (4) to identify the potential influence of IOC, IOS on employees' level of OCS, (5) by fulfilling the above mentioned objectives, this study is an attempt to help organizations to make a better use of their existing IOC plan and fix any flaws affecting the adopted IOS as well as make sure whether their organizational members are satisfied with the previously mentioned variables, IOC and IOS.

\section{RESEARCH QUESTIONS AND HYPOTHESES}

Based, then, on the objectives of the study, the following research questions are set up for the practical research:

1. Research Question 1: Is there any significant relationship between IOC and IOS?

2. Research Question 2: Is there any significant relationship between the existing type of IOC and employees' level of OCS?

3. Research Question 3: Is there any significant relationship between the type of IOS adopted and employees' level of OCS?

The hypotheses emanating from the above research questions are:

1. Research Hypothesis 1: IOC strongly relates to IOS.

2. Research Hypothesis 2: There is a significant predictive link between the existing type of IOC and employees' level of OCS.

3. Research Hypothesis 3: There is a significant predictive link between the type of IOS adopted and employees' level of OCS. 


\section{RESEARCH DESIGN}

The present research is all conducted in two focal organizations, the FLEM and the NSAM, and uses an independent mixed-methods case study research which is equally qualitative and quantitative through the use of one qualitative data collection tool, the semi-structured interview, and one quantitative instrument, the questionnaire. This is for the equivalence of one method in relation to the other within the mixed-methods case study design used; however, for the importance in the research design implementation, timing has been evident in the use of concurrent triangulation methodology as a research strategy. As for the level of interaction that occurs between the quantitative and qualitative strands when implemented, the two strands are kept distinct or independent, and they are only mixed when conclusions are drawn during the overall interpretation at the end of the study.

\section{Sample and Sampling Procedure}

This is one of those times when the essential ingredient for probability sampling, the sampling frame, is impossible for the researcher to construct and the non-probability sampling procedure is the one preferred. Therefore, this type of sampling is shown in the choice of the convenience purposive sample which is chosen here on the ground of the qualitative/quantitative nature of the study and its independent mixed-methods case study research design (Mack et al. 2005; Gravetter \& Forzano, 2011).

\section{RESEARCH INSTRUMENTS}

Since the present study adopts an independent mixed-methods case study design with a focus on concurrent triangulation strategy, the instruments adopted are both of quantitative and qualitative nature, i.e. a scored questionnaire that is used with the purpose to collect quantitative data and is of four parts: A demographic section, an IOC section, an IOS section and an OCS section, and a semistructured interview that could be an explanatory device for identifying trends and relationships revealed in the questionnaire survey. The objective, therefore, of this section is to discuss how the instruments used in this study are developed.

\section{Data Collection Procedure}

Data collection is taken over the course of four months (October through January, 2013). As a preparation for the study, the researcher began the pilot study on 20 employees including 16 managers and subordinates for the survey questionnaire and two managers and two subordinates for the interviews.

\section{Data Analysis Tools}

The data gathered in the present study are analyzed using the most appropriate Statistical techniques. To answer the research questions of the present study, analyses and interpretations are assisted by the Statistical Package for the IBM Social Sciences Program (SPSS), version 20.0. Initially, the negatively-keyed items are reverse coded from "1" to " 5 ", "2" to "4" and so on. Thereafter, the statistical techniques to be used are: First, descriptive statistics such as frequencies, means, and standard deviations are calculated for all dimensions and statements. Second, referential statistics including Chi-square tests, correlations, independent sample T-tests, multiple regression and relations of variance through one-way ANOVA are used. Chi-square tests for independence are used to cross tabulate and analyze qualitative data to test for the statistical independence of the chosen nominal variables relationships.

\section{RESUlts}

\subsection{Data Analysis and Description}

This section is devoted to the description and the analysis of the results. The tools used for data collection are the questionnaire and the semi-structured interview, and the statistical analysis techniques used are frequency distribution, percentages, means, standard deviation, cross-tabulation and Chi-Square Tests, Independent Samples t-Test, One-Way ANOVA, Multiple Regression Analysis and Correlations.

\subsubsection{Findings of the Questionnaire}

A sixty-two-item scored questionnaire is devised to measure the relationship between IOC and IOS and their potential effect on the employees' level of OCS in two case organizations, the FLEM and the NSAM 
The alpha coefficient obtained for the whole questionnaire used in this study using the entire sample is .90 (rounded up from .87 after results of the corrected item-total correlations), suggesting therefore that the items have relatively high internal consistency for the scale used with this specific sample.

The result of factor analysis for the questionnaire indicates that KMO stands at .616 indicating sufficient inter-correlations between the factors and the Bartlett's Test is also significant $\left(\mathrm{X}^{2}=2182.927\right)$ as $p=0.000$ is less than its associated probability value $p<0.005$. That is, the significance level is enough to reject the null hypothesis which further suggests that the original EFA is suitable for the current research.

\subsubsection{Findings of the IOC Questionnaire}

This section of the questionnaire covers 12 items $(\neq 7$ through $\neq 18)$ dealing with two dimensions, formal and informal IOCs and are based on six criteria: Scalar chain, Proof, Relations, Rumors and misunderstanding, Authenticity, and Speed.

Table1. Descriptive Statistics for each IOC Dimension: Formal and Informal IOC

\begin{tabular}{|l|c|c|c|}
\hline IOC Dimension & M & SD & Variance \\
\hline $\begin{array}{l}\text { Informal IOC } \\
\text { (Upward, Downward and Horizontal) }\end{array}$ & 19.42 & 3.92 & 15.39 \\
\hline $\begin{array}{l}\text { Formal IOC } \\
\text { (The Grapevine, chat and gossip) }\end{array}$ & 19.26 & 3.61 & 13.07 \\
\hline Overall IOC & 38.68 & 5.99 & 35.89 \\
\hline
\end{tabular}

Note: Statistically, when the SD is greater than the mean, it means that the group is heterogeneous, but when it is less than the mean, it shows that the group is homogeneous.

It has already been specified, the IOC section, scores scaled from 6.00 to 11.00 represent "never", scores scaled from 11.01 to 22.00 represent "sometimes", and scores scaled from 22.01 to 33.00 represent "always". According to Table 1 above, the mean score of the use of formal IOC among the employees of the two case organizations is $(\mathrm{M}=19.26)$ indicating "sometimes" as an answer with a low spread of the data around the mean $(\mathrm{SD}=3.61)$; in addition, more or less the same mean is scored by the same employees concerning the use of informal IOC $(\mathrm{M}=19.42)$ with a lower spread of data around the mean as well $(\mathrm{SD}=3.92)$. The choice of "sometimes" for the two IOC dimensions indicated by close mean scores is suggestive when it comes to the general mean scores of the employees' use of IOC within their organizations. That is, these employees do not favor any of the IOC dimensions but rather "always" make use of both internally $(\mathrm{M}=38.68, \mathrm{SD}=5.99)$ if it is taken into consideration that the overall score where the mean scores range from 12. 00 to 24.00 represent "never", the mean scores range from 24.01 to 36.00 represent "sometimes", and the mean scores range from 36.01 to 38.00 represent "always".

\subsubsection{Findings of the IOS Questionnaire}

To evaluate the range of the four IOS dimensions, centralization, formalization, stratification and complexity in the two case organizations, a twelve-item measure is used. These structural elements are manifested in organizations in two generic organizational forms: mechanical or organic. Participants are to indicate on a five-point scale the degree, strongly disagree to strongly agree, to which the paired statements describe the IOS of their organization.

Table2. Means, Standard Deviations, and Structural Values of IOS

\begin{tabular}{|l|l|l|l|l|}
\hline IOC Dimensions & \multicolumn{4}{|c|}{ Structural Value } \\
\hline & M & S.D & Organic & Mechanical \\
\hline Centralization & 10.43 & 2.85 & Average & Average \\
\hline Stratification & 10.18 & 3.34 & Average & Average \\
\hline Formalization & 10.35 & 2.55 & Average & Average \\
\hline Complexity & 09.19 & 3.43 & Average & Average \\
\hline Overall IOS & 40.17 & 8.97 & Ambidextrous & Ambidextrous \\
\hline
\end{tabular}

Table 2 above illustrates that the case organizations' overall IOS is ambidextrous in the sense that the mean scores are average, and the data is not spread that much around the mean as the mean score of the High scale ranges from 14.00 to 27.33; the mean score of the Average scale ranges from 27.34 to 40.35 , and the mean score of the Low scale ranges from 40.36 to 54.00. Then, IOS is neither centralized, nor formalized, nor stratified, and neither more nor less complex as the index shows an 
average value ( $M=40.17, \mathrm{SD}=8.97)$. The employees not choosing either of the IOSs is not surprising if their indecision to favour one type of IOC is taken into account. They are discovered to use a mixture of the two types, informal and formal. This runs counter to what has been stated in the literature that the organic IOS correlates and goes hand in hand with the informal type of IOC, and that the mechanical IOS correlates and goes hand in hand with the formal type of IOC.

\subsubsection{Findings of the OCS Questionnaire}

The OCSQ is used to measure the eight OCS factors and the following sub-section provides background information on the components of the OCS questionnaire. Findings are presented in table 3.

Table3. Descriptive Statistics for each OCS Factor in the Two Organizations

\begin{tabular}{|l|l|l|l|l|l|l|l|l|l|}
\hline & & OP & OI & PF & SupC & CC & MQ & HC & SubC \\
\hline \multirow{2}{*}{$\mathbf{N}$} & Valid & 76 & 76 & 76 & 76 & 76 & 76 & 76 & 76 \\
\cline { 2 - 10 } & Missing & 0 & 0 & 0 & 0 & 0 & 0 & 0 & 0 \\
\hline Mean & $\mathbf{1 4 , 2 1 0 5}$ & $\mathbf{1 4 , 2 6 3 2}$ & $\mathbf{1 3 , 9 4 7 4}$ & $\mathbf{1 4 , 3 8 1 6}$ & $\mathbf{1 4 , 0 1 3 2}$ & $\mathbf{1 4 , 9 8 6 8}$ & $\mathbf{1 4 , 0 6 5 8}$ & $\mathbf{1 4 , 4 6 0 5}$ \\
\hline SD & 3,44602 & 2,72455 & 3,20789 & 2,62281 & 3,07026 & 2,38603 & 1,97542 & 1,90746 \\
\hline Variance & 11,875 & 7,423 & 10,291 & 6,879 & 9,426 & 5,693 & 3,902 & 3,638 \\
\hline Minimum & 4,00 & 4,00 & 4,00 & 4,00 & 4,00 & 7,00 & 10,00 & 10,00 \\
\hline Maximum & 20,00 & 20,00 & 20,00 & 20,00 & 20,00 & 20,00 & 20,00 & 18,00 \\
\hline
\end{tabular}

Note: Organizational Perspective (OP), Organizational Integration (OI), Personal Feedback (PF), Supervisory Communication (SupC), Communication Climate (CC), Media Quality (MQ), Horizontal Communication (HC), Subordinate Communication (SubC).

The descriptive statistics for each of the OCS components in table 3 above reveal that the respondents' mean scores on the eight factors is close to the overall OCS mean score $(\mathrm{M}=14.28, \mathrm{SD}=2.66)$ indicating the satisfaction of the employees with IOC within their organizations: media quality $(\mathrm{M}=14.98, \mathrm{SD}=2.38)$, subordinate communication $(\mathrm{M}=14.46, \mathrm{SD}=1.90)$, supervisory communication $(\mathrm{M}=14.38, \mathrm{SD}=2.62)$, organizational integration $(\mathrm{M}=14.26, \mathrm{SD}=2.72)$, organizational perspective $(\mathrm{M}=14.21, \mathrm{SD}=3.44)$, communication climate $(\mathrm{M}=14.01, \mathrm{SD}=3.07)$, horizontal communication $(\mathrm{M}=14.06, \mathrm{SD}=1.97)$, and personal feedback $(\mathrm{M}=13.94, \mathrm{SD}=3.20)$.

The findings obtained for each of the variables under study as well as their potential relationships are discussed as they occurred in the present study. The major objective of this chapter is to discuss and to interpret the quantitative results of the questionnaire together with the qualitative results of the semistructured interview.

\subsubsection{Findings of the Interview}

The objective behind the use of the semi-structured interviews is to explore in depth the features related to the three variables under study: IOC, IOS and OCS. Also, from a triangulation perspective, the idea is to unravel other aspects that the quantitative data collection tool, the questionnaire, is unable to address and reveal (Mitchell \& Jolley, 2012).

The semi-structured interviews are conducted to collect qualitative data. The sample interviewed comprises eight respondents from the two case organizations, four employees each. For each case organization there are two males, one manager and one subordinate, and two females, one manager and one subordinate. The interviewees are employees from the same case organizations and are contacted in place to arrange the interviews date and time. Interviews are scheduled and completed over the course of 30 days (from $19^{\text {th }}$ December 2013 to $17^{\text {th }}$ January 2014). Each interview lasts about 20 minutes and is recorded for the ease of coding and transcription. All interviews follow the semi-structured interview protocol. The interviews are then transcribed for analysis after the respondents' consent.

This section details the findings obtained from the interview data analysis with regard to four major heading themes that are based on the questions included in the semi-structured interview protocol:

1. Participants' perceived opinions of the type of IOC used and the kind of IOS adopted in the two case organizations and the relationship between them.

2. Participants' perceived opinions of the type of IOC used and its effect on their level of OCS. 
3. Participants' perceived opinions of the kind of IOS adopted in the two case organizations and its effect on their level of OCS.

4. Participants' demographics and their effect on their level of OCS.

From the qualitative data findings of both IOC and IOS, it is has been discovered that the employees of the two case organizations deny being involved while deciding upon organizational actors' decisive future; they are irresolute about the requirement whether to use job related titles to address superiors or not; they are also indecisive about whether the IOC nature determines the respect or violation of the directives stated in organizational charts. However, they are clear as to the salience of continuous inservice training in performing their jobs properly and communicating internally well. These qualitative results are similar to the qualitative ones with the exception of the "service" variable, as it has been concluded that there are no significant differences between the services the interviewed employees represent as to their level of OCS within the two case organizations.

From the answers of the interviewees to the first research question that inquires about whether there is a significant link between components of IOC and components of IOS, the qualitative results are similar to the quantitative ones with the exception of "complexity" as the sole IOS dimension where the interviewees differ. Therefore, it can be concluded that there is no significant relationship between IOS and IOC.

As for the second research question that queries about the existence of a significant link between the existing type of IOC and the employees' level of OCS, the qualitative findings of the semi-structured interview reveal that all the interviewed employees are satisfied with the IOC components with the exception of the "suspected" formal IOC and the "old" media adopted and seemingly imposed by the top management and which slow work down, waste time, energy and even money. It is apparently the question that received the majority of votes of those who are satisfied at least with the IOC documentation side.

The third research question investigates whether the employees interviewed are content or not with the type of IOS adopted within their two case organizations. From the results that the semi-structured interview yields, the interviewed employees are unanimously satisfied with the different IOS dimensions with the exception of the "centralization" dimension as they think that the decisionmaking process is monopolized by the top managers. Therefore, it is concluded that there is a significant connection between the different IOS dimensions and the employees' level of OCS. The results of this research question prove that IOS is significantly related to the employees' level of OCS.

The objective of the fourth research question is to determine whether employees differ on their OCS level based on different demographic variables like gender, age, tenure, type of diploma held, supervisory position and service. The qualitative findings of the semi-structured interviews have revealed the same results except for the "service" variable where there are statistically significant differences between the employees in the questionnaire but not among the interviewed employees. This is due, as already mentioned, to a sampling pitfall in the semi-structured interview and in the representation of these employees of only four of the eight services targeted in the questionnaire.

\subsection{Data Discussion and Interpretation}

\subsubsection{Overall IOC and Overall IOS Relationship}

In more details, so as to discover the nature of the link that might exist between overall IOC and overall IOS, the Spearman's rank-order Correlation value $[\operatorname{rho}(24)=-.013, p=.915]$ indicates that there is a small, negative and non-significant connection between IOC $(\mathrm{M}=38.68 ; \mathrm{SD}=5.99)$ and IOS $(\mathrm{M}=40.17, \mathrm{SD}=8.97)$. Therefore, it can be said that the data support the absence of any significant association between IOC and IOS within the two case organizations.

The present study has demonstrated that the employees of the two case organizations do not prefer to use a particular type of IOS and, instead, have the tendency to pursue a structural ambidexterity where features of each structural dimension are mingled out in the same workplace. The findings of the current research support a limited number of studies that preach the ambidexterity of IOS. They back up those of Giles (2002) who states that the content and the meaning of IOC are not necessarily determined by the IOS adopted by the organization. The organizational ambidexterity in the two case organizations is backed up by Kortmann (2012) who states that if strategic management is decentralized, the decision process could be balanced constituting an act of ambidexterity in favour of the employees. 
Many are the reasons why the two case organizations would consider an ambidextrous type of IOS. One has to do with the flexibility of the organizational authority. The respondents in the two case organizations, whether in the questionnaire or in the semi-structured interview, acknowledge the authoritarian nature of IOS as an essential element of the mechanical or hierarchical structures that ultimately defines their organizations. It seems that this type of IOS allows the services to enjoy a greater degree of authority and responsibility within their individual areas which is clear from the delegation of the higher management of some of its responsibilities to the lower organizational echelons.

The second reason has to do with the intention of the higher management in the two case organizations to instruct and to maintain balance in the decision-making process. The objective is to make sure that no single service is able to take actions without clearing them with the higher authorities, particularly that they are done at the organization level giving then a proof of a centralized IOS. They also make sure that some of the individual decisions are taken by the respective services and assume as a result some of the organizational responsibility, proving again the decentralized nature of IOS. Therefore, following this scenario, decision making is concentrated at the top of the organizational hierarchy when it is done at the organization level, and lower down each service has considerable freedom to manage its assigned tasks, and may even be able to work closely with one or two other services in order to complete tasks relevant to both services. This is revealed by the respondents of both case organizations when they emphasized the non-respect of specialization. Many have the tendency to do others' jobs and substitute others in others areas even though they do not possess the required qualifications for doing the work in that service.

\subsubsection{Relationship between IOC and Employees' Level of OCS}

It has been discovered that the two organizations' employees do not prefer any one of the IOC types. Regarding whether there exists any significant predictive link between the existing type of IOC and the employees' level of OCS, a Forced Entry Multiple Regression Analysis is used. The OCS composites are treated as the predictor variables and the IOC composites as the dependent variables. The objective is to discover which DV predicts the best employees' level of OCS in the two case organizations. The analysis has revealed an obvious and a strong predictable relationship between the general score of OCS, $[\mathrm{t}(463)=31.22, p<.05, \beta=.28]$ and IOC. It is safe to conclude that there is a significant predictive link between IOC and all of the OCS components. In addition, the regression model also shows that the best predictors of IOC are, successively, Communication Climate, $[\mathrm{t}(14)=861, \mathrm{p}=.480, \beta=3.01]$, Horizontal Communication, $[\mathrm{t}(14)=3.90, \mathrm{p}<.05, \beta=.45$, Media Quality, $\mathrm{t}(456)=2.75, \mathrm{p}<.05, \beta=.31]$, and Communication with Subordinates, [t(456)=4.23, $\mathrm{p}<.05, \beta=.28]$. This means that the two case organizations' employees, either subordinate or managers, are satisfied with an emancipating IOC that allows them to freely and flexibly communicate internally vertically and horizontally.

Consistent support is found in the literature about the positive relationship that exists between IOC and OCS. Many scholars, as cited in Ragusa (2011), argue that good IOC can boost the employees OCS within any given organization. OCS as an outcome of IOC is improved when the employees participate in the decision-making process that leads to the achievement of the organizational goals, which is not the case of the employees in these two case organizations. It is also enhanced when the employees interact formally and informally, a habit that the employees enjoy while interacting internally; when they have their efforts recognized by the higher management, a fact that the middle managers admit but not the lower rank echelon organizational actors; and when they obtain appropriate in-service training, an aspiration that the employees dream of and never got achieved (Berry, 1981; King et al. 1989).

However, findings of the present study contradict some works stated in the literature. According to Hamilton (2010), employees are less satisfied with the formal IOC than they are with informal IOC. In a survey conducted by Foehrenbach and Rosenberg (1982), it is found that employees are satisfied with downward IOC as they want to be put in the general organizational picture by being kept informed about the organizational tasks and activities as well as the organizational wide concerns and objectives. This runs counter to what is found in the current study because the employees are satisfied with both IOC dimensions given the fact that they use both internally. 


\subsubsection{Relationship between IOS and Employees' Level of OCS}

The third research theme queries about which of the OCS dimensions plays a more influential role on IOS within the two case organizations. To address this theme, a Forced Entry Multiple Regression Analysis is conducted with IOS serving as a criterion variable and the employees' level of OCS serving as a predictor variable. The objective is to assess which of the eight OCS dimensions is predictive of IOS. The results show that the overall regression model is statistically significant $\left[\mathrm{F}(75)=7.192, p<.05, \mathrm{R}=.68, \mathrm{R}^{2}=.46\right]$ suggesting that there is a significant predictive link between the OCS dimensions and all of the IOS components.

In addition to being statistically significant $\left[(\mathrm{R}=.68),\left(\mathrm{R}^{2}=.46\right)\right.$, (adjusted $\left.\mathrm{R}^{2}=.39\right),(\mathrm{F}(75)=7.192)$, $(p<.05)]$, the overall regression model also shows that the best predictors of IOS are successively, Horizontal Communication, [t(76)=6.432, $p<.05, \beta=., 657]$, Organizational Perspective [t(76)=-1.819, $p<.05, \beta=-.202]$, Subordinate Communication $[\mathrm{t}(76)=.825, p=.412, \beta=.090]$, Personal Feedback, $[\mathrm{t}(76)=-1.819, p=.546, \beta=-.078]$, Media Quality, $[\mathrm{t}(76)=.297, p=.768, \beta=.032]$, Communication Climate, [t(76)=.201, $p=.841, \beta=.027]$, Supervisory Communication, [ $\mathrm{t}(76)=.088, p=.930, \beta=.013$ ], and Organizational Integration, $[\mathrm{t}(76)=.050, p=.960, \beta=.006]$.

It is therefore important to mention that the regression analysis reveals an obvious and a strong predictable relationship between the general score of OCS, [ $\mathrm{t}(76)=1.060, p<.05, \beta=.122]$ and the IOS adopted. That is, employees' level of OCS is affected by the existing or rather the chosen ambidextrous IOS that the same employees like to follow to communicate internally.

Basically, little research examines the impact of IOS on OCS; however, there are some studies that are consistent with what has been found in the present study. According to Johnson (1993), it is through the predictable patterns of relationships and the type of IOS adopted that an organization is allowed to process amounts of information where the uncertainty is reduced, and both confidence and satisfaction are developed in the individual employees. IOS is considered as the formal system of task and controlling relationships that coordinate and motivate employees so that they get satisfied to achieve the organization's goals (Jones \& George, 2004). In this regard, Nimmo (1980) suggests that IOS is a chief indicator of OCS. Moreover, according to Phillips and Gully (2011), organizational performance is affected by the type of IOS adopted as a wrongly chosen type of IOS might deter IOC and slow down the work process and hence the way an organization operates. They also stress that IOS is strongly associated with employees' OCS, commitment, as well as turnover. Similarly, Lockman (1983) maintains that among the factors that have the clearest relationship to OCS is the IOS of the organization (cited in Dickey \& Sederer, 2008).

Contrary to what has already been shown by the findings of the present study where the IOS is associated with the degree of the employees' OCS, Klenke (2011) claims that contemporary IOSs are either organic which capitalize on satisfaction, flexibility, and organizational development, or mechanical which seek the maximization of efficiency and production. Similarly, Swansburg and Swansburg (2002) note that within organic IOSs, it is noticed that IOC is vertical, horizontal and lateral and that job design emphasizes personal growth, satisfaction and responsibility as decision making and control are decentralized. Nonetheless, mechanical IOSs are characterized by high organizational formality, pressures, task configuration, and centralization of authority. Surprisingly enough, and in total antithesis to what Klenke (2011) argues, is that the mechanical organizations can produce higher satisfaction among co-workers in formal groups because the hampering bureaucracy does not necessarily exist at lower echelons of the organizational structure.

\section{Conclusion}

The questionnaire contains three scales: the IOC scale which includes formal and informal IOC (12 items), the IOS which comprises four dimensions, centralization, stratification, formalization and complexity (12 items), and the OCS scale which consists of eight dimensions, Organizational Perspective, Organizational Integration, Personal Feedback, Supervisory Communication, Communication Climate, Media Quality, Horizontal Communication, Subordinate Communication (32 items). Various statistical tools are used to test the four advanced hypotheses, Independent Sample T-Test, One-Way ANOVA, the Spearman's Rank Order Correlation, and a Forced Entry Multiple Linear Regression Analysis. Based on the results of the data analysis, $\mathrm{H} \circ 1, \mathrm{H} \circ 4 / 1, \mathrm{H} \circ 4 / 3$ and $\mathrm{H} \circ 4 / 5$ are the null hypotheses accepted. However, the rejected null hypotheses are $\mathrm{H} \circ 2, \mathrm{H} \circ 3, \mathrm{H} \circ 4 / 2$, $\mathrm{H} \circ 4 / 4$, and $\mathrm{H} \circ 4 / 6$ in favour of their research counterparts. 
The employees in the semi-structured interview who are eight in number, four females, two superiors and two subordinates, and four males, two superiors and two subordinates, represent four services from the two case organizations. Their answers are analyzed qualitatively based on the content of the four research questions. The qualitative findings are similar to the quantitative ones except for the "service" variable in the last research question which is due to a sampling pitfall of the services chosen for the semi-structured interview.

\section{REFERENCES}

Atwater, L. E., \& Waldman, D. A. (2012). Leadership, feedback and the open communication gap. New York, NY: Taylor \& Francis Group, LLC.

Bernold, L. E., \& AbouRizk, S. M. (2010). Managing performance in construction. Hoboken, New Jersey: John Wiley \& Sons, Inc.

Berry, W. J., Poortinga, Y. H., Breugelmans, S. M., Chasiotis, A., \& Sam, D. L. (2002). Crosscultural psychology: Research and applications. Cambridge, UK: Cambridge University Press.

Butterick, K. (2011). Introducing public relations: Theory and practice. Ltd. London: SAGE Publications.

Clegg, S. R., Hardy, C., Lawrence, T. B., \& Nord, W. R. (Eds.). (2006). The sage handbook of organization studies. City Road, London: SAGE Publications Ltd.

Cushman, D. P., \& Cahn, Jr. D. D. (1985). Communication in interpersonal relationships. Albany: State University of New York Press.

Downs, C. W., \& Hazen, M. D. (1977). A factor analytic study of communication satisfaction. The Journal of Business Communication. 14(3), 63-73.

Dickey, B., \& Sederer, L. I. (2008). Improving mental health care: Commitment to quality. Washington, DC: American Psychiatric Publishing, Inc.

Foehrenbach, J., \& Rosenberg. K. (1982). How are we doing? Journal of Communication Management, 12(1), 3-11.

Fournier, W. H. (2008). Communication satisfaction, interactional justice, and organizational citizenship. (Doctoral dissertation). Available from ProQuest Dissertations and Theses Database. (UMI No. 3319021)

Giles, H. (Ed.). (2002). Law enforcement, communication, and community. Amsterdam. The Netherlands: Benjamis Publishing Co.

Gravetter, F. J., \& Forzano, L. B. (2011). Research methods for the behavioral sciences. Belmont, CA, USA: Wadsworth Cengage Learning.

Greenbaum, H. H., Clampitt, P., \& Willihngangz, S. (1988). Organizational communication: An examination of four instruments. Management Communication Quarterly, 2(2), 245-282.

Grunig, L. A., Grunig, J. E., \& Dozier, D. M. (Eds.). (2002). Excellent public relations and effective organizations: A study of communication management in three countries. Lawrence New Jersey: Erlbaum Associates, Inc., Publishers.

Hage, J. (1980). Theories of organizations: Form, process, and transformation. New York: John Wiley \& Sons Inc.

Hamilton, C. (2010). Communicating for results: A guide for business and the professions. Boston MA, USA: Wadsworth Cengage Learning.

Hull, F. M., \& Hage, J. (1982). Organizing for innovation: Beyond the burns and stalker's organic type. Sociology, 16(4), 564-577.

Jones, G. R., \& George, J. M. (2004). Contemporary management. Columbus, Ohio: McGraw-Hill School Education Group.

King, S. S. (Ed.). (1989). Human communication as a field of study: Selected contemporary views. Albany: State University of New York.

Klenke, K. (2011). Women in leadership: Contextual dynamics and boundaries. Bingley, UK: Emerald Group Publishing Limited.

Konovsky, M. A., \& Pugh, S. D. (1994). Citizenship behavior and social exchange. Academy of Management Journal, 37(3), 656-669. 
Kortmann, S. (2012). The relationship between organizational structure and organizational ambidexterity: A comparison between manufacturing and service firms. Wiesbaden, Germany: Gabler Verlag, Springer.

Lawrance, P. R., \& Lorsch, J. W (1967). Organization and environment: managing differentiation and integration. Cambridge, MA: Harvard Graduate School of Business Administration.

Mack, N., Woodsong, C., Macqueen, K. M., Guest, G., \& Namey, E. (2005). Qualitative research methods: A data collector's field guide. North Carolina, USA: Family Health International.

Mathisen, G. E., \& Einarsen, S. (2004). A review of instruments assessing creative and innovative environments within organizations. Creativity Research Journal, 16(1), 119-140.

Mitchell, M. L., \& Jolley, J. M. (2012). Research design explained. Belmont, CA USA: Wadsworth Cengage Learning.

Nimmo, D. (1980). Communication yearbook 4. USA: International Communication Association.

Phillips, J., \& Gully, S. (2011). Organizational behavior: Tools for success. Mason, USA: SouthWestern Cengage Learning.

Potosky, D., \& Ramakrishna, H. V. (2002). The moderating role of updating climate perceptions in the relationship between goal orientation, self-efficacy, and job performance. Human Performance, 15(3), 275-297.

Smith, C. A., Organ, D. W., \& Near, J. P. (1983). Organizational citizenship behavior: Its nature and antecedents. Journal of Applied Psychology, 68 (4), 653-663.

Swansburg, R. C., \& Swansburg, R. J. (2002). Introduction to management and leadership for nurse managers. Canada: Jones and Bartlett Publishers, Inc.

Ubben, G. C., Hughes, L. W., \& Norris, C. J. (2007). The principal: Creative leadership for excellence in schools. (6th Ed.). Boston, MA: Allyn \& Bacon.

Van Riel C. B. M., \& Fombrun, C. J. (2007). Essentials of corporate communication. Oxon, USA: Routledge.

Wang, Y., \& Pizam, A. (Eds.). (2011). Tourism destination marketing and management: Collaborative strategies. Oxfordshire, UK: AB International. 